\title{
Individualização, fragmentação e risco social nas sociedades globalizadas
}

Individualization, Fragmentation, and Social Risk in Globalized Societies

Individualisation, fragmentation et risque social dans les sociétés globalisées

\section{Pedro Hespanha}

\section{OpenEdition}

\section{Journals}

Edição electrónica

URL: http://journals.openedition.org/rccs/1253

DOI: $10.4000 /$ rccs. 1253

ISSN: $2182-7435$

\section{Editora}

Centro de Estudos Sociais da Universidade de Coimbra

Edição impressa

Data de publição: 1 Outubro 2002

Paginação: 21-31

ISSN: 0254-1106

Refêrencia eletrónica

Pedro Hespanha, «Individualização, fragmentação e risco social nas sociedades globalizadas » Revista Crítica de Ciências Sociais [Online], 63 | 2002, colocado online no dia 01 outubro 2012, criado a 30 abril 2019. URL : http://journals.openedition.org/rccs/1253 ; DOI : 10.4000/rccs.1253 


\section{PEDRO HESPANHA}

Faculdade de Economia da Universidade de Coimbra e Centro de Estudos Sociais

\section{Individualização, fragmentação e risco social nas sociedades globalizadas}

O autor reflecte sobre os processos através dos quais a globalização está a provocar a corrosão das estruturas de coesão interna nas sociedades contemporâneas e, ao mesmo tempo, a aumentar o risco de marginalização e de exclusão para sectores crescentes da população. A diferenciação social é um desses processos e está relacionado com fenómenos bastante visíveis nas sociedades contemporâneas, como a acentuação das desigualdades, a crescente marginalização de certas camadas e a gradual destruição das solidariedades sociais. O texto começa por analisar dois dos efeitos mais notórios por que o processo de diferenciação social opera - os efeitos de segmentação social e de individualização da vida social -, centrando-se, posteriormente, nas questões do agravamento do risco social e da relativa invisibilidade deste risco.

A sociedade portuguesa é tomada como referência nesta reflexão e os resultados dos estudos realizados no âmbito do projecto "A Sociedade Portuguesa perante os Desafios da Globalização" constituem o capital de prova utilizado.

A temática do painel "Cidadania, Exclusões e Solidariedades" sugere uma reflexão centrada em torno dos processos através dos quais a globalização está a provocar a corrosão das estruturas (mais ou menos consolidadas) de coesão interna nas sociedades contemporâneas e, ao mesmo tempo, a aumentar o risco de marginalização e de exclusão para sectores crescentes da população. Tratando-se de uma realidade generalizada a todo o globo, ela assume na sociedade portuguesa contornos particulares devido à posição de Portugal no contexto da economia mundial e, por isso, a sociedade portuguesa será tomada como referência nesta reflexão, que toma como base os resultados dos estudos realizados no âmbito do projecto "A Sociedade Portuguesa perante os Desafios da Globalização” (Hespanha e Carapinheiro, 2002).

Começarei por caracterizar e relacionar entre si os processos de mudança associados à globalização e, ao mesmo tempo, por dar conta da sua novidade relativamente a processos aparentemente semelhantes ocorridos em momentos anteriores. Posteriormente, serão abordados os problemas 
da invisibilidade desses processos e do sentido que eles tomam na sociedade portuguesa.

A diferenciação social é um dos processos associados à globalização que permite explicar fenómenos bastante visíveis nas sociedades contemporâneas, como a acentuação das desigualdades, a crescente marginalização de certas camadas e a gradual destruição das solidariedades sociais. Ela opera através de um duplo efeito. Por um lado, um efeito de segmentação social, consistindo na descolagem dos segmentos mais débeis dos grupos sociais situados na base da sociedade e na promoção dos mais fortes situados no topo. Por outro, um efeito de individualização da vida social, ou seja, uma maior autonomia dos indivíduos relativamente às estruturas colectivas de autoridade baseadas na tradição ou no poder do Estado.

O modo como a globalização produz estes efeitos não é linear, tal como o não é a própria globalização - um conjunto complexo de processos, movidos tanto por influências políticas como económicas. Deste ponto de vista, fragmentação e individualização são apenas manifestações das mudanças ocorridas no nosso quotidiano e nas instituições em que assentam as nossas sociedades em resultado da conjugação desses diferentes processos.

1. A fragmentação social, na acepção que lhe foi dada acima, pode relacionar-se mais facilmente com os processos da globalização económica, ainda que não esgote nelas a sua compreensão. ${ }^{1}$ No entanto, o fenómeno é muito complexo precisamente porque passa por uma tensão dialéctica entre a integração de novos espaços sociais necessária à expansão das oportunidades no mercado global e a fragmentação dos grupos sociais devida à diferente dotação de recursos para aproveitar essas oportunidades. $\mathrm{Na}$ formulação expressiva de Octávio Ianni, "globalização rima com integração e homogeneização da mesma forma que com diferenciação e fragmentação" (Ianni, 1997: 32). O que parece importante reter é o facto de que o aproveitamento das oportunidades está condicionado pela disponibilidade de recursos materiais, tecnológicos e organizativos e de que essa disponibilidade de recursos está desigualmente repartida pelos grupos sociais, regiões e países (ibid:: 134). Na mesma linha, Therborn refere como beneficiários principais das oportunidades criadas pela globalização os indivíduos, as classes ou os sectores mais produtivos; quem se mostre capaz de aumentar as oportunidades através da extensão dos mercados; quem se mostre capaz de utilizar as instituições e as medidas de política e quem disponha de mais amplas competências no domínio dos conhecimentos e da comunicação (Therborn, 1999: 76).

${ }^{1}$ Sobre a tensão entre fragmentação cultural e homogeneização moderna, cf. Santos, 2001: 53. 
Esta argumentação acerca da capacidade diferencial de os indivíduos e os grupos aproveitarem as oportunidades não é incompatível com o reconhecimento de que certos efeitos de igualização possam ter-se verificado à escala mundial. Por exemplo, no que respeita à produtividade, este último autor aponta a experiência europeia de redução das diferenças de produtividade agrícola entre países e regiões, durante as décadas de 50 e 60, na sequência da introdução ampla de melhoramentos técnicos (ligada a processos de industrialização, racionalização agrícola e urbanização), para admitir que a globalização da produtividade agrícola pode bem representar no futuro um efeito igualizador ascendente.

No entanto, parece prevalecer o efeito amplificador das desigualdades no capitalismo global à medida que este se expande e aprofunda e isto por força das suas próprias contradições: por um lado, a contradição entre a necessidade de concentração do capital e a de fragmentação dos processos de produção (dialéctica da concentração versus fragmentação); e, por outro, a contradição entre a necessidade de obter trabalho barato e a de expandir a procura de novos mercados consumidores (dialéctica da exclusão versus inclusão) (Chossudovsky, 1997: 17; Dupas, 1999: 195).

É precisamente a procura de eficiência e competitividade para a conquista de novos mercados que conduz ao processo de fragmentação da produção. Este opera por intermédio de uma série de expedientes - como a externalização dos custos, o franchising, a subcontratação ou a informalização - que asseguram o controlo económico dos sectores juridicamente autonomizados relativamente à empresa-mãe. Os estudos sobre as cadeias produtivas e as redes de empresas do capitalismo globalizado mostram que só aparentemente a fragmentação da produção e a deslocação das actividades propriamente produtivas para os segmentos periféricos da cadeia afectam a autonomia da grandes empresas transnacionais. $\mathrm{Na}$ realidade, através de um vasto conjunto de expedientes de dependentização e da reserva das decisões estratégicas de captação dos mercados, elas controlam toda a cadeia produtiva e determinam a parcela de lucro que deve ser distribuída em cada elo da cadeia (Dupas, 1999: 51).

$\mathrm{Na}$ sua análise do sistema de cadeias globais de empresas, Gilberto Dupas identifica as diferentes fases do processo pelo qual uma grande quantidade de pequenas empresas alimenta a cadeia produtiva central com custos relativamente baixos. É frequente as cadeias globais estarem fortemente fragmentadas e, à medida que se caminha do topo para a base, elas apresentam-se cada vez mais constituídas por segmentos dotados de grande flexibilidade e informalidade no emprego localizados em países ou regiões onde o trabalho é abundante e barato. A estratégia de redução dos custos 
usa a fragmentação para deslocar os segmentos mais intensivos em trabalho e de menor qualificação profissional para localizações mais favoráveis.

Diversos estudos têm sido feitos para mostrar como a lógica das cadeias globais afecta a qualidade e a quantidade da oferta global de emprego (Dupas, 1999: 197). De uma forma geral, eles mostram a afirmação de um conjunto de tendências que apontam para uma crescente desqualificação do emprego globalizado: o emprego directo está a dar lugar a formas de emprego indirecto (contratos de prestação de serviços, subcontratação, franchising, etc.), a criação de empregos qualificados perde peso relativamente à de empregos não qualificados, a flexibilização torna-se um padrão para os novos empregos, o recurso ao trabalho informal na base das cadeias aumenta progressivamente.

Saldando-se, em geral, por um agravamento do desemprego formal e pela flexibilização e insegurança do trabalho, o sistema de emprego que se está a instituir através do novo modelo global de produção representa um agravamento do risco social e da exclusão para um crescente número de trabalhadores espalhados por todo o espaço mundial. "Enquanto selecciona, reduz, qualifica - e, portanto, exclui - no topo, a nova lógica das cadeias inclui na base trabalhadores com salários baixos e contratos flexíveis, quando não informais" (Dupas, 1999: 71).

2. Passemos agora ao segundo processo: a individualização. Tem sido chamada a atenção para o facto de que, no mundo de hoje e em especial nos países mais ricos, o que move as pessoas é cada vez mais ter uma vida própria. Ter dinheiro, trabalho, poder, amor ou uma crença religiosa, sendo objectivos importantes, revelam-se pouco fiáveis enquanto modos de realização pessoal e isto de acordo com princípios éticos que estão a tornar-se dominantes. "Qualquer tentativa de criar um novo sentido de coesão social tem de partir do reconhecimento de que o individualismo, a diversidade e o cepticismo estão inscritos na cultura ocidental" - avança Ulrich Beck (Beck e Beck-Gernsheim, 2002: 23).

Isto não significa, contudo, reconhecer o primado da autonomia individual tal como professa o pensamento liberal desde o Iluminismo. Como reconhece Zygmunt Bauman, a individualização é antes o resultado de uma fatalidade, ou seja, ninguém pode escapar a dela. Mesmo quando as pessoas não têm consciência disso, as condições de existência "chegam sem ser convidadas e recusam-se a partir quando as pessoas o desejam" (Bauman, 2001: 17). O afastamento entre as vidas narradas e as narrativas vividas, entre as biografias e as autobiografias chega a ser muito elevado. As pessoas aceitam, acreditam e agem como se fossem culpadas dos seus próprios problemas: no caso de doença, culpabilizam-se por não terem seguido um 
regime mais saudável; no caso de desemprego, por não se terem preparado para a entrevista ou esforçado bastante para encontrar um emprego; no caso de falta de perspectivas no emprego, por não terem investido tanto quanto deviam em fazer amizades ou em impressionar os chefes (Beck e Beck-Gernsheim, 2002: xvi).

Parece intrigante que, de repente e em simultâneo, muitas pessoas queiram assumir o controlo das suas vidas. "O que é que explica o zelo, o receio e o entusiasmo, a astúcia e a determinação com que tanta gente se preocupa e luta pela 'sua própria vida'?” - interroga-se Beck. A resposta é dada por um vasto número de factores que, segundo ele, compelem os indivíduos a (procurar) aumentar a sua autonomia pessoal. Sintetizarei aqui o essencial da argumentação deste autor (Beck e Beck-Gernsheim, 2002: 22 ss.).

Primeiramente, os factores relacionados com a própria diferenciação interna das sociedades e com a especialização das instituições modernas. $\mathrm{O}$ argumento é que, dado que as instituições integram cada vez mais os indivíduos apenas em aspectos parciais e efémeros das suas vidas, eles são forçados a agir por sua conta e risco e a tomar em mãos a defesa dos seus interesses para evitar que as suas vidas sejam despedaçadas. Agir, nessas circunstâncias, implica tornarem-se activos, inventivos e mobilizarem recursos. Esta atitude gera também uma mudança essencial: os indivíduos passam a considerar-se produtores activos das suas vidas e não meros reflexos passivos das circunstâncias que os envolvem. Daí que a necessidade de agir por si próprio venha a converter-se num sentimento de responsabilização pessoal pelos resultados e que, por essa via, os problemas sociais tendam a ser convertidos em disposições psicológicas - sentimentos de culpa, ansiedades, conflitos e neuroses - e as crises sociais em problemas individuais.

Segundo, os factores relacionados com o controlo institucional. De acordo com Beck, a individualização gera as próprias condições institucionais em que os indivíduos são separados das seguranças tradicionais ao mesmo tempo que perdem o acesso aos direitos básicos e aos recursos oferecidos pela modernidade, ou seja, em que os indivíduos se tornam excluídos. O que até recentemente orientava e organizava a gestão do quotidiano dos indíviduos - o valor normativo das tradições - é substituído por orientações e regulamentações institucionais que, deixando aparentemente uma maior margem de escolha aos indivíduos (por exemplo, quanto às obrigações no domínio da educação, do trabalho ou da segurança social), vão exigir deles um esforço de auto-organização muito maior do que anteriormente para evitar que uma escolha errada afecte irremediavelmente as suas vidas. A burocracia e a selva institucional tornam-se, deste modo, verdadeiramente sufocantes para os indivíduos e geram neles uma reacção de sobrevivência 
que consiste em não contar senão consigo próprios, aumentando os campos de autonomia pessoal e desvinculando-se das lealdades institucionais. Por seu turno, não funcionando mais as soluções herdadas do passado para enfrentar os novos problemas, os indivíduos têm de procurar novas soluções cujos efeitos não conhecem. A gestão da vida, imposta por exigências conflituantes e por um contexto de incerteza global, torna-se, neste sentido, experimental e arriscada.

Uma consequência particular deste aspecto da individualização, para que chamam a atenção vários autores, é a corrosão e a lenta desintegração da cidadania. Uma e outra explicam-se, desde logo, pelo atrofiamento do espaço público. Para Zygmunt Bauman, o espaço público tende a ser preenchido pelas preocupações dos indivíduos enquanto tais, que reclamam a sua legitimidade exclusiva para ocupar esse espaço e expulsam do discurso público qualquer outra preocupação. “O 'público' é colonizado pelo 'privado'; o 'interesse público' é reduzido à curiosidade sobre as vidas privadas de figuras públicas e a arte da vida pública é reduzida à exposição pública de assuntos privados e à confissão pública de sentimentos privados (quanto mais íntimos melhor). As 'questões públicas' que resistem a essa redução tornam-se incompreensíveis" (Bauman, 2001: xviii).

Sabe-se também como o novo individualismo (que Beck faz questão de qualificar de individualismo institucionalizado, para o distinguir do velho individualismo liberal de mercado ou do individualismo neoliberal de tipo thatcheriano) representa uma ameaça para as solidariedades sociais. Ao centrar no indivíduo toda a sua acção providencial, o Estado acaba por contribuir decisivamente tanto para o deperecimento das velhas solidariedades horizontais entre os indivíduos como para a subalternização ou mesmo a omissão de uma acção providencial orientada para as famílias, os grupos e as comunidades. Deste modo as responsabilidades e a obrigação mútua dos indivíduos entre si vão-se diluindo ao mesmo tempo que a cidadania, enquanto direitos e obrigações face ao Estado, se vai cada vez mais individualizando. Em sentido algo diferente deste, Boaventura de Sousa Santos associa o processo de individualização ao regresso do mercado e sublinha o facto de a aspiração de autonomia, criatividade e reflexividade surgida como reacção a uma cidadania atomizante e estatizante se ter convertido em privatismo, dessocialização e narcisismo por força da compulsão consumista e da difusão social da produção capitalista. Narcisismo e autismo seriam as marcas de uma subjectividade sem cidadania (Santos, 1994: 220).

Finalmente, e para concluir este ponto, o processo de individualização coloca um paradoxo de implicações políticas importantíssimas. $\mathrm{O}$ paradoxo consiste em que a acção e a imaginação políticas se confrontam com 
desafios a uma escala sem precedentes; precisamente quando os processos de individualização estão a corroer as condições sócio-estruturais para o consenso político. O facto é que a individualização está a conduzir a uma despolitização da política, no duplo sentido de que predomina uma mobilização partidária dos cidadãos que é cega e independente das preferências destes e de que é reduzido o número de actores colectivos politicamente activos e reduzida também a sua homogeneidade interna.

A importância e actualidade desta reflexão parece indiscutível, mesmo para sociedades, como a portuguesa, em que o processo de individualização parece não se ter difundido ainda ao mesmo ritmo dos países mais desenvolvidos (Beck e Beck-Gernsheim, 2002: 206). Ainda assim, não deixa de ser significativo que, num dos estudos realizados, se conclua que os processos de mudança detectados estão "a pulverizar a combatividade de classe e as capacidades de emancipação colectiva, dando lugar a formas economicistas de acção, a padrões de consumo individualistas e a atitudes subjectivas de pendor conformista e adaptativo" (Estanque, 2002: 79). Por isso, cremos que o fenómeno da individualização dos pobres, objecto de tratamento abundante em muitos países, constitui um dos domínios de aplicação mais produtivos da teoria da individualização no caso português devido à sua capacidade de explicar o crescimento generalizado das desigualdades sociais.

3. Qual a relação entre estes dois processos da globalização e o risco social?

Sabe-se como nas economias capitalistas contemporâneas a assunção activa do risco constitui um elemento central do dinamismo económico e da inovação social. Arriscar tornou-se sinónimo de mudança. No entanto, risco é também sinónimo de incerteza dos resultados e de probabilidade acrescida de aparecimento de efeitos não desejados ou mesmo inesperados numa economia mundializada. A noção de risco social associada à globalização emerge, assim, deste contexto.

Por outro lado, as mudanças profundas ocorridas nas instituições sociais (relacionadas, por exemplo, com os novos modelos de família ou de estilos de vida) tornam os resultados das decisões individuais em certos domínios da vida quotidiana menos previsíveis e aumentam o grau do risco (Giddens, 1999: 28). Casar, empregar-se, montar um negócio são acompanhados hoje de um grau de incerteza muito elevado quanto aos resultados porque os contornos das instituições que sustentam tais actividades já não são os mesmos.

A questão do risco assume um papel importantíssimo no quotidiano dos trabalhadores, pois as novas condições de um mercado de trabalho flexível obrigam um grande número de pessoas assumir riscos, mesmo sabendo 
que as probabilidades de sucesso são reduzidas. "Numa sociedade dinâmica, as pessoas passivas definham" (Sennet, 2001: 103). Um exemplo da análise dos efeitos conjugados dos processos de fragmentação e individualização no quotidiano dos trabalhadores é a estimulante obra de Richard Sennett, $A$ corrosão do carácter. Aí se analisam as consequências que as novas formas de trabalho do capitalismo globalizado provocam nos comportamentos dos indivíduos. "Não jogar significa a aceitação antecipada do nosso fracasso. A maioria das pessoas que entra num mercado em que 'o vencedor leva tudo', embora saiba da probabilidade do fracasso, suspende esse conhecimento e tal como acontece quando o risco ocorre em condições menos determinadas, a excitação imediata da sorte grande ajuda a anular o conhecimento racional sobre a probabilidade de sucesso. Mas, ainda que essas pessoas permaneçam lúcidas até ao fim, não fazer nada parece-lhes mais passividade do que prudência" (Sennett, 2001: 106).

A questão da individualização merece também alguma reflexão adicional quando se constata a popularidade dos modelos de trabalho em equipa nas empresas mais avançadas. Para Sennett não existe propriamente uma nova cultura da cooperação, mas sim um elaborado processo de encenação (e uma estratégia de sobrevivência) através do qual a posição dos que dominam a equipa sai reforçada, ficando a cooperação limitada a aspectos superficiais e contingentes da relação de trabalho. O tão propalado novo comunitarismo do trabalho em equipa é, na realidade, um princípio organizativo muito débil precisamente porque não valoriza as diferenças, em privilégios e poder, que existem nos membros das equipas.

Sendo certo que o risco comporta, em geral, um lado positivo - a probabilidade de alcançar as vantagens esperadas - e um lado negativo - a probabilidade de ter de suportar desvantagens esperadas -, o que parece específico no caso do risco social associado à globalização é a desigual repartição dos aspectos positivos e negativos pelos diferentes grupos e espaços sociais. Neste sentido, torna-se muito importante analisar o papel das instituições e, designadamente, dos Estados-Providência - mas também das instituições supranacionais -, na gestão do risco social através de meios de segurança e de protecção social para a eventualidade de produção de riscos.

Quando se analisa deste ponto de vista o caso português, Portugal parece constituir um bom exemplo de uma sociedade muito vulnerável aos impactos negativos da globalização económica. Pela sua condição semiperiférica no contexto mundial, o país apresenta certas características que favorecem uma elevada abertura à penetração das formas hegemónicas de globalização, tais como a debilidade dos seus mecanismos de regulação - económica, social ou cultural - e a sua elevada heterogeneidade social (Santos, 1993). 
Esta última característica - a elevada heterogeneidade social da sociedade portuguesa - é responsável, não só por uma particular vulnerabilidade aos processos de globalização, mas ainda por um desigual e contraditório impacto desses processos nos diferentes sectores da sociedade. Dadas as relações próximas que existem entre os fenómenos da globalização e da modernização em sociedades de desenvolvimento intermédio, como Portugal, as diferenças entre os vários segmentos de uma mesma sociedade tornam-se particularmente relevantes nesta matéria. Neste sentido, os segmentos menos modernizados da sociedade detêm menor capacidade de resistência ou de negociação face aos efeitos globalizadores e, por isso, sofrem os efeitos mais destrutivos.

Os estudos de terreno realizados mostram, a este propósito, que "a operacionalidade da sociedade-providência para compensar a ausência de políticas e minimizar os efeitos excludentes do capitalismo global fracassa nos estratos mais baixos da sociedade, nos grupos sociais mais marginalizados e menos dotados de recursos. Aí, a ajuda recíproca encontra enormes dificuldades para se impor, devido à falta de meios para pagar os favores por parte de quem carece de ajuda. Aí, os indivíduos agem sob a pressão das necessidades básicas de sobrevivência e, incapazes de cumprir as regras de uma sociedade providente, ficam à margem dela numa situação próxima do estado de natureza" (Hespanha et al., 2002: 50).

4. Finalmente, a questão da invisibilidade dos processos da globalização. Não sendo a globalização apenas algo que está fora e distante dos indivíduos, mas antes um fenómeno que convive com estes e influencia decisivamente os aspectos pessoais das suas vidas, importa reconhecer que os efeitos desta globalização que incidem sobre os quotidianos dos indivíduos são relativamente invisíveis.

Os estudos realizados parecem confirmar esta asserção. Em nenhum deles foram encontrados sinais claros da presença de factores de globalização económica: não houve instalação ou encerramento de fábricas integradas em cadeias produtivas transnacionais, não houve deslocação de trabalhadores atraídos pelas soft global cities nacionais, não houve imposições drásticas instituídas por políticas económicas de ajustamento.

Como escreve Octávio Ianni, "o globalismo não nasce pronto, acabado, e muito menos presente, visível e evidente. Revela-se aos poucos, seja à observação, seja ao pensamento. Aparece e desaparece, conforme o lugar, o ângulo de visão, a perspectiva ou a imaginação. Umas vezes parece inexistente e outras, se mostra evidente, estridente (Ianni, 1996 :218)

Boaventura de Sousa Santos introduziu a designação de globalização de baixa intensidade para recobrir situações precisamente como esta em que, 
apesar de não serem aparentes os vectores globais, eles não deixam de estar presentes e de produzir os seus efeitos. Por vezes, esses vectores encontram-se mascarados sob a aparência de outros fenómenos, como a modernização, a compulsão ao consumo ou o endividamento. Outras vezes, eles manifestam-se apenas pelo imobilismo ou pela descolagem de certos segmentos sociais ou de certos espaços relativamente a outros mais dinâmicos, ficando inexoravelmente para trás na cena mundial.

Afigura-se-nos que as respostas locais são muito difíceis de compreender, porque quando as pessoas reagem às mudanças que afectam as suas vidas, estas mudanças têm em geral uma ligação muito frouxa com os fenómenos globais. Quando se analisam, por exemplo, os factores de mal-estar em populações rurais, a maior parte deles relacionam-se com o contexto de vida imediato dessas populações - tais como as dificuldades em vender os produtos, a falta de empregos fora da pequena agricultura, a falta de serviços ou de equipamento social, a perda de poder de compra, etc. Mesmo nas cidades, onde o mal-estar aparece associado à degradação ou precaridade da habitação, à falta de emprego ou à burocracia exagerada e ineficiência dos serviços, os factores mais remotos que desencadeiam esse mal-estar permanecem quase sempre ocultos e escapam, assim, à percepção das pessoas.

Porque os impactos de um fenómeno global são em geral associados ou mediados por outros fenómenos ou macroprocessos - como as políticas do Estado, o papel de intermediação das elites locais, a difusão da informação, etc. - a nível local torna-se muito difícil distinguir os agentes da mudança ou os factores de mal-estar. Por isso, designamos esta forma de globalização de insidiosa e excludente.

O que permite afirmar que a crise social vivida por certos estratos da população decorre dos fenómenos de globalização - associados, repetimos, a fenómenos de outra natureza - é o facto de esses estratos se mostrarem impotentes para aproveitar as oportunidades de mudança que permitiram aos restantes estratos aceder a níveis de vida mais avançados. $\mathrm{O}$ aumento das desigualdades, medido pelo afastamento crescente dos padrões de vida dos estratos mais pobres relativamente aos dos mais ricos e também aos padrões de vida médios, é a manifestação mais visível daqueles fenómenos. E o que vale para os indivíduos vale também para os territórios. Nesta dialéctica de exclusão-inclusão, os espaços que não se revelem funcionais do ponto de vista nova lógica do sistema global são deixados para trás, dando lugar a formações sociais crescentemente dualizadas. 


\section{Referências Bibliográficas}

Beck, Ulrich; Beck-Gernsheim, Elisabeth (2002), Individualization. London: Sage.

Bauman, Zygmunt (2001), La sociedad individualizada. Madrid: Catedra.

Chossudovsky, M. (1997), The Globalisation of Poverty. London: Zed Books.

Dupas, Gilberto (1999), Economia global e exclusão social. Pobreza, emprego, Estado e o futuro do capitalismo. São Paulo: Paz e Terra.

Estanque, Elísio (2002), «A recomposição das classes face aos impactos da globalização: Classes, subjectividade e participação num contexto semi-rural», in Hespanha e Carapinheiro (orgs.), 55-80.

Giddens, Anthony (1999), The Runaway World. How Globalisation is Reshaping our Lives. London: Profile Books.

Hespanha, Pedro et al. (2002), «Globalização insidiosa e excludente. Da incapacidade de organizar respostas à escala local», in Hespanha e Carapinheiro (orgs.), 25-54. Hespanha, Pedro; Carapinheiro, Graça (orgs.) (2002), Risco social e incerteza. Pode o Estado social recuar mais?. Porto: Afrontamento.

Ianni, Octávio (1997), A era do globalismo. Rio de Janeiro: Civilização Brasileira.

Santos, Boaventura de Sousa (1993), «O Estado, as relações salariais e o bem-estar social na semiperiferia: O caso português», in B. S. Santos (org.), Portugal: Um retrato singular. Porto: Afrontamento, 17-56.

Santos, Boaventura de Sousa (1994), Pela mão de Alice. O social e o político na pós-modernidade. Porto: Afrontamento.

Santos, Boaventura de Sousa (org.) (2001), Globalização: Fatalidade ou utopia? Porto: Afrontamento.

Sennett, Richard (2001), A corrosão do caráter. As consequências pessoais do trabalho no novo capitalismo. Rio de Janeiro: Record.

Therborn, Goran (1999), «Dimensões da globalização e a dinâmica das (des)igualdades», in Pablo Gentili, Globalização excludente. Desigualdades, exclusão e democracia na nova ordem mundial. Petrópolis: Vozes. 